\title{
How Conservation Strategies Contribute to Sustainable Development
}

\author{
by \\ JEFFREY A. MCNEELY \\ Chief Conservation Officer, \\ The World Conservation Union (IUCN), \\ Avenue du Mont-Blanc, 1196 Gland, Switzerland.
}

\section{INTRODUCTION}

Judging from both increased media coverage and heightened political interest, the environment seems to have become one of the hottest issues of our time. Governments and the general public appear to have accepted the theme and major argument of the report of the World Commission on Environment and Development (WCED): The time has come for a marriage of economy and ecology, so that governments and their people can take responsibility not just for environmental damages, but also for the policies that cause the damage. In this they should increasingly look to the future.

'The challenge facing nations today', the WCED (1987) stated in its report, 'is no longer deciding whether conservation is a good idea, but rather how it can be implemented in the national interest and within the means available in each country.' Alas, therein lies the problem. What is the national interest, and why are insufficient means made available for conserving biological resources? This paper suggests that the answers to both those questions come from the field of economics, and outlines how conservation strategies can draw on economics to support government policies which will promote forms of development that are sustainable in the long run.

\section{Why Are Biological Resources Being Depleted?}

Many answers have been provided to the question of why biological resources are being so depleted. But most answers address symptoms - poaching, encroachment, exotic species, and so forth - rather than the more fundamental issues. One important factor that is often ignored is that the world's biological resources are being overexploited because the world is functioning as a single system, so that local ecosystems, and especially agro-ecosystems, can be exploited by distant markets. Those earning the benefits from exploitation can therefore ignore local environmental costs of their exploitation, instead passing on those costs to local communities or future generations. Small wonder, then, that resource exploitation is so profitable: the benefits flow to the cities and to the foreign markets, while the environmental costs are felt directly by the local communities whose cries of anguish are easily ignored.

Costs and benefits are seriously out of balance, because different institutions are responsible for different sides of the equation, and the benefit side of the ledger gets most of the attention; forestry revenues are not compared with fisheries losses due to sedimentation, and conservation authorities never seem to have the funds or the land required to conserve biological diversi- ty effectively. Decision-makers like to approve projects that will earn money and provide employment, and the public is often convinced of the wisdom of these efforts, even if the projects carry hidden long-term costs that may saddle future generations with major debts and leave few resources to develop (Pearce, 1975; Clark \& Munn, 1986; Perrings, 1987; McNeely, 1988).

Decision-makers make such decisions inter alia because the consumers have become accustomed to a great diversity of goods coming from afar. Let us consider a hypothetical, though practical, illustration of how the world is linked together. Oil from Saudi Arabia fuels the machines and makes the fertilizers and pesticides which allow marginal land in West Africa to grow, on trees originating in tropical America, a crop of cocoa for Switzerland to make into chocolate which is flown on American-made airplanes to Singapore for distribution in south-east Asia; the profit made by the West African farmer allows him to purchase a Japanese motorcycle, Ethiopian coffee, and Thai rice. No longer vulnerable only to local ecological factors, the West African farmer is now maintained by a complex of international commodity agreements, market forces, and the many other factors which enable the world to function as a single system. The farmer's destiny is controlled by factors that may lie even farther beyond his influence than does the weather.

In many parts of the world, the overexploitation of forests, energy, and fisheries, is designed not primarily to support the direct material needs of local people, but rather to produce commodities to sell overseas to earn foreign exchange for further investment in all manner of things - including resource exploitation and the imported goods that people now seem to require. The production of these imported goods often entails environmental degradation in other parts of the world, and carries numerous hidden costs (euphemistically called 'externalities' by economists).

If the forces that cause the exploitation of natural resources lie in the fields of commerce, foreign relations, energy, defence, and agriculture - usually the sectors of real power in a government - how may the relatively weak and invariably ill-funded conservation agencies be reasonably expected to have much impact on how those resources are exploited? If the conservation NGOs focus their attention on such symptoms as poaching and pollution, rather than on the economic roots of those problems, how effective can they really expect to be? And if the wealthy industrialized nations suffer from such problems, imagine how much worse things must be for the poor tropical nations which are struggling just to ensure that their citizens have a full belly when they curl up on a bamboo mat to go to sleep at night. 


\section{Strategic Approaches to Conserving THE NATURAL HeRITAGE}

So what can be done? How can overexploitation of resources be transformed into new approaches which will enable at least the renewable natural resources to be used on a sustainable basis? To provide an answer that is at least as simple as the way I have defined the problem: We need to ensure (1) that all the relevant institutions share the same information, (2) that the problems are defined in ways that are mutually agreed and will lead to acceptable solutions, and (3) that broad objectives of development are agreed to by all the major players.

This three-steps' process sounds easy, but agreements on none of these three elements - information, problem definition, and objectives - is easy to reach, and all of them are affected by political, economic, and social, factors that seem to defy solution. However, knowing the difficulties must not impede action, for the cost of inaction is likely to be global environmental bankruptcy.

It is easy to be discouraged and feel overwhelmed by the complexity of the challenges which are inherent in our modern consumer society. But however perilous our journey may be, we will surely feel greater confidence if we have some navigational aids - a compass, a map, and a guide-book, or their equivalents - which tell us where the hazards lie, and which roads are most likely to avoid the obstacles and enable us to reach our destination unharmed.

Applying this principle to conservation of biological resources - whether acting at community, national, or global, level — strategies are still needed to guide conservation actions, to provide general maps and aids to guide us on our now-or-never voyage to sustainable development. Such strategies can be at the global level, in the manner of the The World Conservation Strategy (IUCN, 1980); the sector level, such as the Tropical Forestry Action Plan (FAO, IBRD, WRI, \& UNDP, 1986); at the institutional level, such as the Botanic Gardens Conservation Strategy (IUCN-WWF, 1989); at the national level, such as various national conservation strategies (see below); or at a whole range of other levels. A brief review of a few of these follows.

\section{National Conservation Strategies}

One means of initiating improved policy coordination is through preparing a national conservation strategy (NCS), which is basically an extremely broad national environmental management plan (IUCN, 1984). An NCS can form the basis of a new, broader-than-formerly, pattern of well-balanced development that depends primarily on the conservation of natural resources. Great and lasting benefits are to be gained by bringing the processes of conservation and development together. The preparation of national conservation strategies will assist countries to realize this potential by facilitating the definition of policies and actions - including the conservation of biological diversity, upon which sustainable development can be built.

The first requirement for a successful NCS is the participation of the widest possible range of 'actors' in defining the issues and identifying possible courses for action. Preparing an NCS involves government agencies, non-governmental organizations, private interests, and the community at large, in analysis of natural resources issues and assessment of priority actions. In this way, sectoral interests can perceive better their interrelationships with other sectors, and new potentials for conservation and development can emerge or be revealed. No matter how broadly-based a government may be, the nature of the public sector (or indeed of any centralization of power) limits the range of issues which can be considered effectively. The NCS process places government in partnership with NGOs, citizens' groups, universities, industry, financial institutions, and many other factions, in seeking to relate the use of biological resources to national development objectives. It therefore provides an important (and generally non-threatening) forum for reaching national consensus about policies on the use of biological resources. Few better mechanisms seem likely to exist.

In one form or another, the NCS process has been initiated in over 40 countries. Focusing on national planning and the range of decisions taken by the public sector on the use of biological resources (either deliberately or by default), an NCS can address many of the most fundamental policy issues which are faced by governments that are seeking to use their biological resources on a sustainable basis.

Several other tools have been developed to incorporate what once were regarded as external considerations in development policy decisions. Environmental Impact Assessment (EIA) is one such tool, and its application has yielded many benefits (Ahmad \& Sammy, 1985). Yet EIA generally offers only guidance when once fundamental choices among available options have been taken. The NCS approach, in developing a framework where environmental concerns can be related to development objectives, offers the possibility to approach a more appropriate balance-point than otherwise through a process of consensus-seeking.

\section{International Strategies for Linking Conservation with Development}

At the global level, conservation strategies must (1) provide the basic information about the status of resources and the trends in their use, (2) define problems in terms that are convincing to the sectors of society which have the real power over resource use, and (3) agree as to the objectives which should guide development action (Jacobs \& Munro, 1987). Strategies are turned into action through a more tactical process of planning specific activities to address the broad strategies or parts of them; this often involves the preparation of an action plan which is relevant to a particular sector or community, such as a national park management plan or a regional land-use plan. But the broader strategy is needed to set the agenda, and specify where the linkages between sectors need to be forged.

At all levels, conservation of biological resources must be seen as part of the development process, as the development process must be based on the sustainable use of forests, wildlife, and water; for these resources will renew themselves if they are managed properly. The 
WCED (1987) has pointed out that environment and development are not separate challenges, but are inexorably linked. 'Development cannot subsist upon a deteriorating environmental resource base', said the Commission: 'The environment cannot be protected when growth leaves out of account the costs of environmental destruction. These problems cannot be treated separately by fragmented institutions and policies. They are linked in a complex system of cause and effect.'

Dividing responsibilities into sectoral units leads to poor coordination, conflicting directives, fragmentation of effort, and waste of time and money. This can be overcome only by determining how decisions in one sector affect the ability of another sector to depend on the same resources. What does demand for timber in Japan do to Indonesia's fisheries, tourism, or agriculture? What are the implications of global warming for Soviet defence policies? Will a dust-bowl to the south stimulate massive migrations northwards across Canada's borders? What happens to fur-trapping rural communities when wellmeaning NGOs in Europe change public attitudes and cause antipathy against the wearing of fur coats?

Many policies outside the traditional conservation sector can have fundamental effects on biological resources, so action in any one sector will not necessarily solve any problem. Instead, conservation needs to be woven together with agriculture, forestry, fisheries, commerce, transport, national defence, and other efforts, with the whole based on a sound scientific assessment of the status and trends of species and ecosystems both at home and abroad (Caldwell, 1984; OTA, 1987).

The importance of those linkages was clearly pointed out in the World Conservation Strategy (IUCN, 1980), which presented a series of policy actions at international, national, and local, levels. The response to the WCS has been positive and lasting, but circumstances have changed and much has been learned in the past 10 years. For these reasons, IUCN is now working with WWF and UNEP - its partners in the WCS - on a new version which will meet the new challenges of the 1990s. It will cover all aspects of sustainable resource development, concentrating on identifying the priority issues and the actions that are most likely to tackle them effectively. As the main strategy document will be short (40 pages or so), detailed treatment of particularly important aspects of these issues will be left to companion strategy documents. The Global Strategy for Conserving Biological Resources - being prepared by the World Resources Institute, IUCN, and UNEP, in collaboration with numerous other institutions from all parts of the planet - will be one of these companions.

But pointing out the linkages - that is, providing information - is only part of the picture. As a next step, the problems need to be defined in ways that will encourage the different sectors to work together with a set of common objectives. Such integration is not easy, and in some respects it is not very practical. Nevertheless, an optimal balance-point can be found where the benefits of considering broad impacts match the costs of doing so; in most cases, this balance-point lies well beyond the current practice of taking decisions based on a very narrow range of sectoral considerations, without thinking of questions of long-term sustainability.

\section{Strategic Policies for Conservation}

As government policies often lead to the depletion of biological resources, it stands to reason that changing these policies is often a necessary first step towards conservation. Several major policy-components might be covered in a strategy that is aimed at fostering integrated action:

First, put in US dollar or other leading currency terms, are the many economic and financial benefits of linking development with conservation of biological resources. Money is a universal solvent, and it is often the language that speaks loudest to those in positions of real power (Hufschmidt et al., 1983). Not all the benefits of conservation can be expressed in dollars; but more than many people think can be so expressed. We must learn to get better at this task (McNeely, 1988).

Second, identify compatibilities among different resource-uses, and ways in which such uses can be enhanced. Watershed protection, fishing, hunting, tourism, and scientific research, can often be accommodated in the same area if these different uses are carefully planned and managed.

Third, be open and objective about any conflicts that may exist between agriculture, fisheries, forestry, mining, wildlife management, conservation, and habitat rehabilitation. Hiding the truth benefits nobody, but exposing the facts - however harsh they may be - can often lead to a basis for a new consensus.

Fourth - and this is a crucial point - recognize that our existing governmental institutions and procedures are not evolving nearly as quickly as our environmental problems emerge, so that new institutions may be required to design and implement integrated development plans and programmes. Many of our institutions and procedures are senile or close to it. They need rejuvenation or replacement by more vigorous and innovative ones.

Fifth, make sure that lines of responsibility are clearly defined, and that those who are responsible for exploitation also share the responsibility for conservation. The recent major oil-spill in Alaska dramatically demonstrates the dangers that can result when resource-exploiting industries ignore such responsibilities. In many cases - especially with forests, fisheries, and wildlife assigning (or returning) more management responsibility to a local community may be an effective part of a conservation strategy.

Finally, recognize that the best motivation is often enlightened self-interest; consequently, effective incentives may need to be devised to close any gap between what the individual sees as an investment benefit and what the government considers to be in the national interest.

\section{LESSONS LEARNED}

Based on nearly half-a-century of experience in over 120 countries, IUCN has found that conservation strategies can provide the best 'map' for stimulating and coordinating integrated conservation activities. Cartographers seeking to provide such guidance might wish to consider a few of the lessons which IUCN has learned along the way. 
First, recognize that preparing a conservation strategy is a process, and that the process should be infinitely more important and attractive than the mere production of a document. Linkages and partnerships that are forged during the process may last far beyond the date of publication, and indeed such abiding relations should be planned as part of the process.

Second, make sure that the process of preparing the strategy involves those who will be affected by it, either as beneficiaries or implementers. It is also important to ensure that the strategy addresses real needs - of the areas or species concerned, of the implementing institutions, or of the human communities involved.

Third, use the process of strategy preparation to build political and financial support, both among governments and with other institutions which may be able to contribute; if the real sources of power cannot be brought on board, then the strategy will surely fail to generate action.

Fourth - a point that is so obvious that it is often overlooked - make sure that the conservation strategy contains policy advice and recommended actions that are both necessary and sufficient to solve the problems which had been identified or might foreseeably emerge.

Fifth, make sure that the process of preparing a conservation strategy includes the means to monitor its implementation, and to make necessary adjustments as the actions for which it calls are implemented.

Finally, make sure that the strategy contains clear ideas about how its policy recommendations are going to be implemented; in other words, make sure that the 'map' is accompanied by a 'guidebook', and that those who are going to use the latter can readily understand its directions.

The 'guidebook' or action plan is required to address the specific needs of geographic areas - such as nations, regions, or protected areas - and to address particular topics, such as the global network of protected areas and groups of species and varieties. National conservation strategies, environmental profiles, river basin plans, regional development plans, and other existing approaches, can be amended where necessary to incorporate conservation considerations.

The 1990s must be a time of intensive action, involving major national and international investments in conserving our biological heritage. As the eminent Harvard biologist Edward O. Wilson recently commented: 'How the human species will treat life on Earth, so as to shape this greatest of legacies, good or bad, for all time to come, will be settled during the next 10 years.' Conservation strategies can help to guide the actions that will enable this generation of humans to enrich rather than impoverish the Earth, and to give their descendents a fair chance of an equable life.

\section{ACKNOWLEDGEMENTS}

Numerous colleagues at IUCN have contributed to the ideas contained in this paper, especially Martin W. Holdgate, Mark Halle, David A. Munro, and Kenton R. Miller. A version of the paper was presented at the 'Conference on Heritage and Sustainable Development', held in Ottawa, Canada, on 14 May 1989. Support for the preparation of the paper was received from the Governments of Switzerland, Norway, Sweden, and Finland.

\section{SUMMARY}

The world is now so tied together by flows of energy, information, and commodities, that action in one part of it is likely to have implications for many other parts. Numerous biological resources - particularly wildlife and forests - are being depleted more by foreign demand than by direct local consumption. Money earned by depleting resources is then often invested in imported industrial products, which themselves may have had negative environmental impacts in the country of their production. As examples we may cite certain pesticides which, on being banned in the countries of their production, are exported to others.

Solutions to conservation problems must address both overt symptoms such as disappearing forests, and the more fundamental issues underlying the symptoms, such as human overpopulation and profligacy. Whether conservation action is aimed at local communities, river basins, sectors, nations, or regions, overall strategies are required to establish a common base of information, to define the problems in ways that will lead to their solution, and to agree on objectives for action. An essential element in all such strategies is to describe the linkages to factors which are external to the immediate system, and to assess how those external factors will affect any actions that are being proposed.

\section{REFERENCES*}

Ahmad, Yusuf \& Sammy, G.G. (1985). Guidelines to Environmental Impact Assessment in Developing Countries. Hodder \& Stoughton, London, England, UK: $52 \mathrm{pp}$.

BernsteIn, B.B. (1981). Ecology and economics: Complex systems in changing environments. Annual Review of Ecology and Systematics, 12, pp. 309-30.

BOARDMAN, R. (1981). International Organizations and the Conservation of Nature. Indiana University Press, Bloomington, Indiana, USA: 215 pp.

BORMAN, F.H. (1976). An inseparable linkage: conservation of natural ecosystems and the conservation of fossil energy. BioScience, 26, pp. 754-60.

CALDWELL, L.K. (1984). International Environmental Policy: Emergence and Dimensions. Duke University Press, Durham, NC, USA: $367 \mathrm{pp}$.

CARPENTER, R. (Ed.) (1983). Natural Systems for Development. Macmillan, New York, NY, USA: 485 pp.

Clark, W.C. \& MUNN, R.E. (Eds) (1986). Sustainable Development of the Biosphere. Cambridge University Press, Cambridge, England, UK: $491 \mathrm{pp}$.

Dasmann, R.F., Milton, J.P. \& Freeman, P. (1973). Ecological Principles for Economic Development. John Wiley \& Sons, London, England, UK: $252 \mathrm{pp}$.

FAO, IBRD, WRI \& UNDP (1986). The Tropical Forestry Action Plan, FAO, Rome, Italy: $32 \mathrm{pp}$.

*Including 16 that are not cited in the text but are retained at the Author's request because of their particular pertinence. Note that our 'full' style of citation is not followed in this compilation, especially in the matters of prelim. pages and illustrations. - Ed. 
HALl, D.O. Myers, N. \& MARGaris, N.S. (Eds) (1985). Economics of Ecosystems Management. W. Junk Publishers, Dordrecht, The Netherlands: $347 \mathrm{pp}$.

HufschmidT, Maynard M. et al. (1983). Environment, Natural Systems, and Development: An Economic Valuation Guide. Johns Hopkins University Press, Baltimore, Maryland, USA: $338 \mathrm{pp}$.

IUCN (1980). World Conservation Strategy: Living Resource Conservation for Sustainable Development. IUCN-UNEPWWF, Gland, Switzerland: $44 \mathrm{pp}$.

IUCN (1984). National Conservation Strategies: A Framework for Sustainable Development. IUCN, Gland, Switzerland: 52 pp.

IUCN-WWF (1989). Botanic Gardens Conservation Strategy. IUCN-WWF, Avenue du Mont-Blanc, 1196 Gland, Switzerland: viii +56 pp., maps \& figs.

JACOBS, P. \& Munro, D. (Eds) (1987). Conservation With Equity: Strategies for Sustainable Development. IUCN, Gland, Switzerland: $466 \mathrm{pp}$.

McNeELy, J.A. (1988). Economics and Biological Diversity: Developing and Using Evonomic Incentives to Conserve Biological Diversity. IUCN, Gland, Switzerland: $232 \mathrm{pp}$.

MCNEELY, J.A. \& Miller, K.R. (Eds) (1984). National Parks, Conservation, and Development: The Role of Protected Areas in Sustaining Society. Smithsonian Institution Press, Washington, DC, USA: $838 \mathrm{pp}$.

OECD (1982). Economic and Ecological Interdependence. Organization for Economic Cooperation and Development, Paris, France: 28 pp.

OLDFIELD, Margery (1984). The Value of Conserving Genetic Resources. US Department of Interior, National Park Service, Washington, DC, USA: $360 \mathrm{pp}$.

Organization of AMERICAN STATES (1987). Minimum Conflict: Guidelines for Planning the Use of American Humid Tropic Environments. OAS, Washington, DC, USA: $198 \mathrm{pp}$.
OTA (US Congress, Office of Technology Assessment) (1987). Technologies to Maintain Biological Diversity. US Government Printing Office, Washington, DC: 334 pp.

Pearce, D.W. (1975). The Economics of Natural Resource Depletion. Macmillan, London, England, UK: 435 pp.

PERRINGS, C.A. (1987). Economy and Environment: A Theoretical Essay on the Interdependence of Economic and Environmental Systems, Cambridge University Press, New York, NY, USA: $192 \mathrm{pp}$.

PIGRAM, J.J. (1980). Environmental implications of tourism development. Annals of Tourism Research, 7(4), pp. 554-83.

PRESCOTT-Allen, R. (1986). National Conservation Strategies and Biological Diversity. Report to IUCN, Gland, Switzerland: 67 pp.

Prescott-Allen, R. \& Prescott-Allen, C. (1982). What's Wildlife Worth? Economic Contributions of Wild Plants and Animals to Developing Countries. International Institute for Environment and Development (Earthscan), London, England, UK: $92 \mathrm{pp}$.

Prescott-Allen, C. \& Prescott-Allen, R. (1986). The First Resource: Wild Species in the North American Economy. Yale University Press, New Haven, Connecticut, USA: 529 pp.

RANDALl, Alan (1979). Resource Economics: An Economic Approach to Natural Resource and Environmental Policy. Grid Publishing, Columbus, Ohio, USA: 321 pp.

RePETto, Robert \& Gillis, Malcolm (Eds) (1988). Public Policies and the Misuse of Forest Resources. Cambridge University Press, Cambridge, England, UK: 432 pp.

WORLD BANK (1988). Wildlands: Their Protection and Management in Economic Development. World Bank, Washington, DC, USA: 278 pp.

World Council on Environment and Development (cited as WCED) (1987). Our Common Future. Oxford University Press, Oxford, England, UK: $383 \mathrm{pp}$. 